\title{
3 Do robots care?
}

\section{Towards an anthropocentric framework in the caring of frail individuals through assistive technology}

\author{
Andrea Bertolini, Shabahang Arian*
}

\section{Abstract}

As a consequence of modern medicine and modern style of living, two demographic trends, namely longevity and a decline in fertility have greatly increased the aging population. The number of older persons aged 60 years or over is expected to be 1.4 billion by 2030 (World Population Data 2017). This demographic change combined with changes in family structure challenges the future of elderly care, and contributes to grounding a case towards the use of advanced robotics and AI to either integrate or radically replace human-provided services in this field.

This paper introduces an anthropocentric framework - as defined by the European Commission in its 2018 Communication on AI - for the care of elderly individuals through assistive robotic technologies. Firstly, the concepts of care and cure are distinguished, followed by a critical analysis of the function of robots in the context of care. The paper continues with an analysis of the aforesaid technologies with the notion of care provided to highlight that machines have the potential to interact and simulate a relationship, but not to establish a real meaningful one with the user. User's deception and deprivation of a meaningful care-relationship is discussed as a potential risk emerging from an incorrect use of technology in the treatment of fragile individuals, and the fundamental legal principle of human dignity is considered with respect to its potential application and impact on policies in this domain, as an objective criterion that poses limits also to the individual's freedom of self-determination.

\subsection{Introduction}

According to the International Federation for Robotics (IFR 2016), between 2016 and 2019, circa USD $\$ 97$ million worth of robots will be sold for the care of the elderly and people with disabilities. Due to two parallel and tightly interconnected trends the world is facing, the considerable growth of aging population (Lutz, Sanderson, and Scherbov 2008) and increasing research in assistive technologies, many countries are considering introducing robotic applications in the care of the elderly (Flandorfer 2012). These technologies are intended as an addition to more traditional, human-performed practices, to integrate said services and in some instances as a replacement of solutions that appear burdensome for current and future welfare budgets.

* Shabahang Arian: Chapter 3.1-3.4; Andrea Bertolini: Chapter 3.5-3.8

Ә Open Access. (C) 2020 Andrea Bertolini, Shabahang Arian, published by De Gruyter. (c) BY-NC-ND This work is licensed under the Creative Commons Attribution-NonCommercial-NoDerivatives 4.0 License. https://doi.org/10.1515/9783110677485-003 
As the world population ages, the Potential Support Ratio (PSR) or the ratio of the working-age population is reduced. This situation is alarming for policymakers as lower PSR means more elderly persons will become dependent on fewer younger workers. Prior to 1950, PSR was about 12 workers for every pensioner; today there are just 8 and by 2050, the number will be decreased to 4 workers for every pensioner (Yale Global 2015). Moreover, the care management of older adults with multi-morbidity and complex chronic conditions is a more complicated task to perform by non-professional caregivers and it requires in-depth knowledge and expertise in the field of geriatric care (De Vos 2017). Professional and skilled caregivers observe optimal care according to multifactorial geriatric problems of the elderly in their clinical decision-making and implement different clinical intervention based on each individual specific or co-existence condition (American Geriatric Society 2012).

Increased life expectancy and the need for skilled professional caregivers will likely escalate the health expenditure in aged care services. Therefore, many countries around the world are seeking strategies to deal with these challenges and to reduce healthcare costs.

In light of the foregoing, rapid technological advances together with the rise of social and assistive robotics, appear as an appropriately and timely solution, driving a potential shift in the way care is provided (Salvini 2015). Whilst current research addresses product safety and reliability (Bertolini 2013) juxtaposed with perfecting the functioning of aforesaid devices, ethical concerns emerge with respect to the replaceability of human carers in the treatment of the patient (Sharkey and Sharkey 2010).

The proposed anthropocentric framework aims to establish the criteria of "standard of care" for assessing the application of care robots. The framework set out in this paper highlights the relational and emotional dimension of care and the corresponding need to assess the use of robotics in the treatment of vulnerable individuals. Consideration is given to the concept of human dignity in the context of extant legal systems and the legitimizing of care robots for the treatment of fragile individuals. Existing technologies, together with those currently under development, are discussed together with the characteristics they possess and the functions they are capable of serving.

\subsection{Care vs. cure}

To cure is defined as overcoming suffering and restoring well-being (Oxford English Dictionary 2018). Indeed it is a natural human tendency to avoid illness and attempt to improve the overall quality of life. Disease makes people incapacitated and reduces their ability to pursue their goals. For this reason, throughout human history, the vulnerable human species constantly searched for cures and improvements, and medicine emerged as a science to overcome or at least to lessen its symptoms.

Such natural inclination at times transforms into the radical desire of overcoming all vulnerabilities, eventually achieving eternal life and eternal youth. Technology, in 
this context, is perceived as the key liberating element that through sufficient funding is able to express its potential without any external restriction or limitation beyond mere scientific constraints and can fulfil the awaited promise (Bostrom 2005). However, such an account is flawed as no technological advancement can ever eradicate all human vulnerabilities since they are inherent to the human condition (Coeckelbergh 2013) and even to human nature (MacIntyre 1999). Indeed, once a scientific advancement tackles one specific limitation, illness or impairment, a new one will emerge as a consequence thereof (Coeckelbergh 2013).

Care isinsteada moral characteristic of human beings, anda fundamental element of human relationships. The termitself stems from the Latin word cura which has a twofold meaning, namely that of care (attention, treatment) and cure (restoring of health). Care addresses the "multi-dimensional" sphere or overall "well-being" of the person that encompasses the physical, mental, economic, social, political and spiritual condition of any individual (Calzo 2018).

The verb "to care" defines an "attitude of concern for the well-being of another" and "care" is a practice of caring for others (Oxford English Dictionary 2018). Scholars ${ }^{6}$ coming from various disciplines provide a number of alternative definitions (Tronto 2015; Engster 2007) all revolving around the notion of the human condition (Arendt 1958) that encompasses the multifaceted dimension of human beings without reducing it to a single physical or psychological parameter. Thus, it is rooted in the relational dimension of every human as a social animal (Aristotle,1988). It exceeds the notion of cure, for it may not be measured in purely medical terms, and instead amounts to a socio-emotional relationship among aroup of individuals that values the well-being of others. Care extends beyond the mere observable improvement in an individual specific medical condition and thus might be defined according to two fundamental dimensions, namely (i) relational, and (ii) emotional.

\subsubsection{Care is relational}

The notion of care would not be objectively taken into account if there is no concern for others. Care is associated with the engagement of at least two parties (Noddings 1984), including parents, children, pets or plants. Relationships depend on the "con-

\footnotetext{
6 Tronto defines care as "species activity that includes everything we do to maintain, continue, and repair, our world so that we may live in it as well as possible. That world includes our bodies, ourselves, and our environment, all of which we seek to interweave in a complex, life-sustaining web." Engster describes caring as "a practice encompassing everything we do directly to help individuals satisfy their basic biological needs, develop or maintain their basic capabilities, and avoid or alleviate pain and suffering." Madeline Leininger defines caring as "those assistive, supportive, or facilitative acts toward or for another individual or group with evident or anticipated needs to ameliorate or improve a human condition or lifeway.
} 
nection" of given objects which typically share some common interests within a given network. However, in some networks, relationships are merely aimed at achieving certain goals and interests, and do not go beyond that specific objective. For instance, taking care of a plant for it to grow and remain healthy requires constant attention. Care in such a context entails improving the plant's environment, reap its fruits and contemplate its natural beauty. However, no trust or respect is established through this exchange. In contrast, other relationships, such as that established between humans are fundamentally underpinned by qualities such as communication, understanding, integrity, solidarity, sincerity, compassion, benevolence, reliability and advancement. The doctor-patient relationship constitutes a good example in this sense, for doctors cannot merely prescribe a clinical treatment without initially building a socially meaningful connection with patients. Indeed, physicians establish effective communication with patients by listening carefully to their feelings and sufferings, and responding appropriately to their needs. Integral to this relationship are both compassion and empathy.

\subsubsection{Care is a deeply engaging emotion}

Compassionate relationships are central to human well-being. Reich describes "care" as "a deeply engaging emotion/idea that has confronted and challenged rationalist, abstract, and impersonal systems of thought, with far-reaching social, political, ethical, and religious implications" (Reich 1995). The concept of care is synonymous with emotional engagement, affection and regard between cared for and cared about. Moreover, human touch is considered a fundamental resource for communication, sociality and care. The emotional dimension is observed in the attitude of affection and regard between carer and cared for, that often presupposes prioritising the needs and interests of the latter over those of the former, and transposes in what is at times referred to as "human touch"; a fundamental resource for human communication, sociality, closeness and therefore, care. Compassionate care in the context of aging parents equates to treating older loved ones with respect and dignity when their health has declined and they are incapable of accomplishing tasks independently. Displaying empathetic and affectionate manners towards them (e.g. kissing, cuddling) gives the impression that they are wanted, and of high priority. This in turn enables the vulnerable individual to preserve a status of well-being that, as defined by the World Health Organization (WHO 1948), does not amount to the mere absence of illness but presupposes experiencing the attention and concern of others who enter this relational dimension. 


\subsubsection{Care is a virtue}

The ethics of care is only a few decades old. However, Aristotle uses Philēsis and to philein to demonstrate what defenders of the ethics of care mean by "caring" and "care" (Curzer 2007). Aristotle defines to philein as "wishing for [others] what you believe to be good things, not for your own sake but for [theirs], and being inclined, so far as you can, to bring these things about" (Aristotle 1984).

The ethics of care gives more attention to caring as a foundation for morality (Noddings 2013; Reich 2001). Indeed Reich (2001) stated, "If we do not care about others (and ourselves), or about human tasks or human ideals and goals, we are incapable of any moral knowledge, judgment, or action".

As Coeckelbergh (2013) asserts, any individual human is vulnerable and acknowledging it simply entails to understand our nature and condition, since in some part of our lives at least, we necessarily depend upon others. We all need to be cared for and nurtured in different moments and circumstances of our lives, from birth to our natural end (MacIntyre 1999). In this regard, frailty is not to be deemed problematic or pathologic, but simply inherent to human nature and allowing for the flourishing of our relational dimension. Humans express themselves through the interaction that bonds one individual to the others, and indeed, the concept of human flourishing, is a practice of such common good, which is served by a network of giving and receiving. The virtues of independence and of acknowledged dependence as MacIntyre claimed, may draw our attention to the moral value of care and concern for the needs of children, the elderly or people with disabilities (MacIntyre 1999).

\subsubsection{Care for the elderly}

Traditionally, the practice of care - in particular for the elderly - was rooted among family members. In traditional proximate families, the exchange of care is constituted by ritualized face-to-face conversations, bodily contact and daily interactions among members characterized by physical co-presence (Falicov 2007). However, massive social changes caused a progressive disruption of the "traditional" extended family, and income inequalities ever more induce young generations to be on the move uprooting themselves geographically, culturally, and economically to find a better life (Fischer and Tronto 1999; Schmalzbauer 2010).

In contemporary societies, institutional care is a substitute for family-oriented patterns of care, in order to provide care for the elderly. While care for older people through non-member family caregivers can be morally understandable, it is important to give the elderly a sense of belonging, regard, and comfort in the vulnerable stage of their lives. The virtue of acknowledged dependence is the commitment of the community to address the needs, values, and best interest of the elderly in providing care for them. 


\subsection{The need for robot carers}

As a consequence of modern medicine and modern style of living, two demographic trends, namely longevity and a decline in fertility, have significantly increased the aging population. Furthermore, the number of older persons aged 60 years or over is expected to be 1.4 billion by 2030, more than double by 2050 and to more than triple by 2100 (The World Population Prospect 2017). Globally, the number of persons aged 80 or over is projected to increase to 909 million by 2100 , nearly seven times its value in 2017 (UN Aging 2018).

This demographic change, combined with changes in family structure will be very challenging for the future of elderly care. As world population ages, the potential support ratio (PSR) or the ratio of the working-age population reduces. This situation is alarming for policymakers because the lower PSR means more elderly depend on fewer younger workers. Prior to 1950, PSR was about 12 workers for every pensioner; today there are just 8 and by 2050 the number will decrease to 4 workers for every pensioner (Yale Global 2015). More specifically, the care management of older adults with multimorbidity and complex chronic conditions is much more complicated a task to perform by non-professional caregivers and it clearly requires in-depth knowledge and expertise in the field of geriatric care (De Vos 2017). Professional and skilled caregivers shall observe optimal care according to multifactorial geriatric problems of frail elderly in their clinical decision-making and implement different clinical intervention based on each individual specific or co-existence condition (American Geriatric Society 2012).

Increased life expectancy and the need for skilled professional caregivers will likely escalate the health expenditure in aged care services. Therefore, many countries around the world are seeking strategies to deal with these challenges and to reduce healthcare costs.

In such a perspective, rapid technological advances and above all the rise of social and assistive robotics, might appear particularly apt and timely, driving a potential shift in the way care is provided (Salvini 2015).

\subsection{Care robotics and assistive technologies: An overview}

"Care robots" or "social robots" are being considered as facilitators to support the process of caregiving to the elderly at home. Japan is predictated to be the first super aging society with a dependency ratio of about $73 \%$ by 2050 (OECD 2018). To manage this challenge, the Japanese government is currently introducing a nationwide system of robotic assistive technologies for aged care and has intensified its investments of the development of so-called assistive technologies (Flandorfer 2012).

In Europe, where the old-age dependency ratio is expected to reach $49 \%$ by 2050 , the European Union is induced to finance the development of assistive technologies, 
including those resorting to the use of robots, also through its major research programs, such as Horizon 2020.

Similarly, the United States subsidizes the development of robotic assistive technologies whose innovative potential is presumed to be comparable to that of the Internet and modern media (US Robotics Roadmap 2016); despite its expected old-age dependency ratio it is estimated to reach $34 \%$ by 2050, therefore substantially lower than the two geopolitical areas above recalled.

Whether such approaches are to be adopted as the ideal solution of a clear societal challenge, is a matter that rests on articulate considerations. The theoretical framework provided to define the notion of care, distinguishing it from that of cure, is but one of the two fundamental pillars of the reasoning here more broadly conducted. The second is, however, the technological one. It is therefore necessary to define those functions that robotic assistive technologies are typically called in to perform. In this respect some references of existing application as well as emerging trends are discussed below.

\subsection{The functions of care robots}

The primary functions existing care robots aim at serving are threefold: assist, monitor, and provide companionship, respectively (Sharkey and Sharkey 2010).

Some applications are designed to be an aid in performing daily tasks. A viable example is "Bestic", a device intended to assist people with some disabilities with feeding themselves autonomously, without the intervention of a human carer. The lack of human assistance in the completion of such a simple yet essential task is empowering, at least so long as the user is not isolated as a consequence thereof. Indeed, on the one hand, achieving independence in quite an intimate sphere positively contributes to the self-perception of the user feeling less incapacitated and limited by his condition. On the other hand, the circumstance that a human carer is not involved in the material completion of the task, favors human interaction. On the premise that another human is present, the meal can develop into an occasion for meaningful

\footnotetext{
7 Bestic is an assistive eating and drinking aid which is programmed to assist the action of picking up food from the plate. The user can pilot a robotic arm that has a spoon attached by pressing a button to pick up the food from the selected area of the plate (Nylander, Ljungblad, and Villareal 2012), Information may be found at https://www.camanio.com/us/products/bestic/. There are other products on the market that are similar to Bestic, such as the Meal Time Partner, a battery operated robotic assistive eating device, and My Spoon, a meal assistant robot with similar characteristics that can pick up the desired food from the tray by changing the joystick.
} 
interaction, certainly improving the overall quality of life of the user (Dag, M. et al. 2017)..$^{8}$

Other robots are instead designed to supervise and monitor frail individuals. "Pearl" is a nurse robot that reminds seniors about routine activities (e.g. eating, drinking, taking medicine and doctor appointment) (Pollack et al. 2002) and can monitor various health parameters such as heart rate and blood pressure (Mickelburgh 2004). In similar cases, automation still replaces some otherwise purely human occasions of interaction. Typically, a nurse would perform said tasks and, during those very moments, exchange some words and establish some form of human bond with the patient. However, the mere automation of surveillance does not necessarily lead to the radical exclusion of human-human interactions.

Both such applications, attempting to automatize the completion of repetitive tasks, not to establish a connection with the user, may therefore appear to serve a purely instrumental purpose that may eventually - despite questionably, for they are not causing the lessening of disturbing symptoms, or an improvement in the medical condition - amount to cure, certainly not care, as defined above. Overall, their correct use - not instead their abuse, as tools leading to the substantial replacement of professional carers - would also not limit, much less exclude, the occasions of human interactions, ultimately appearing less if not un-problematic on ethical, legal and subsequently policy grounds.

In a different way, the so-called "social companion robots" are specifically designed to challenge, stimulate and interact with the user on a social, emotional, and personal level, either for the purpose of serving a given and peculiar therapeutic use or, more broadly, to contrast the loneliness and isolation of the fragile individual. As per the former, Paro 9 , a baby harp seal-like robot, simulates emotions and responses to external stimuli such as temperature or sound, once it is patted or called. The bot is primarily used in the treatment of patients with dementia (Shibata and Wada 2010) and indeed, studies indicate that Paro has a positive psychological effect on the mental state and well-being of the user (Sheba et al.2018; Birks et al. 2016; Hamada et al. 2008). Some studies demonstrate the positive effect of the use of Paro in the treatment of patients affected with dementia, and depression, as well as those displaying agita-

8 The report of users with intellectual disabilities (ID) and their assistants who experienced using Bestic as their eating aid highlights first of all, according to assistants, eating aid did not increase the users' independence to decide and making choices in everyday life and as a concept of "self-determination". However, their assistants mentioned that the eating contributed to the users deciding how often food was put in the mouth. Secondly, the other important problem was in regard to limitation in functionality which was different based on the types of food being chosen. But the main question in this context was whether giving users a long time without any "social interaction" with humans could have affected the users' willingness and motivation to use Bestic. The study show that users decided not to continue using it. (Dag M. et al. 2015).

9 Paro Therapeutic Robot, information may be found at http://www.parorobots.com/ 
tive behaviors, as the robot is capable of producing a calming effect ${ }^{10}$. Typically, such beneficial effect is observed with respect to one specific parameter, such as - in the case at hand - "positive affectivity"11. At the same time, users also demonstrate verbal and non-verbal empathetic reactions towards the machine, whose artificial nature they are not capable of discerning. (Demange et al. 2018).

However, the range of interactions offered by social robots are quite limited. As such their ability to fully replace humans in care is also extremely limited. Indeed, the reason why designers modelled Paro upon the appearance and behavior of a seal-pup rather than any domestic pet is that, whilst considered cute and thus capable of triggering positive emotional reactions, the limited direct experience the average person has with any wild animal reduces user's expectations about the robot's behavior in multiple circumstances. Moreover, the limited user knowledge and understanding of what a seal-pup does simplifies the technological challenge of replicating it in a satisfying way, causing its functioning to become plausible. However, the true challenge companion robots are facing is that of replicating more complex, skilled, and articulate social interactions, of the kind that could be perceived as radically replacing human ones.

An example in that sense is provided by Jibo, an application developed by MIT, intended to become "your new best friend". The device was designed in collaboration with Pixar and is primarily intended to interact with humans in a home environment to entertain them, and provide company, irrespective of whether they are children to babysit, elderly living alone, or young single adults at the beginning of their independent life. Indeed, Jibo failed to function as expected. The aforementioned issues, however, primarily limited on current technological constraints that further advancements could clearly overcome. Indeed, the intention of developers was to produce a machine whose primary function is that of emotionally engaging the user and ultimately replacing the apparently equivalent and corresponding - yet radically and ontologically different - human relationship.

\footnotetext{
10 According to one assessment conducted by trained neuropsychologist in a geriatric hospital in Paris, the overall "positive affectivity" of patients improved over the three-month period of the treatment. The study also found that the intervention of Paro had a remarkable effect on a group of patients who were suffering from depression and agitative behaviors. In respect to the latter, it must be noted that agitation is more related to disturbing environmental stimuli (e. g. disruption of routines, lack of relatives, or under- or overstimulation), and Paro has a promising calming effect in this regard and could reduce cortisol level due to tactile stimulation

11 Positive affectivity is a trait that refers to stable individual differences in the experience of positive emotions and active engagement with one's surroundings. Individuals who are high in positive affectivity tend to be cheerful, enthusiastic, energetic, confident, and alert. (Lopez 2013).
} 


\subsection{The ethical admissibility of caring through technology}

This paper argues that there is a need to critically assess the ethical admissibility of both current and future uses of care robots. Indeed, the authors refute the transhumanist idea that asserts the only constraint in the use of technology should be that determined by scientific and technical advancement itself, for not everything that is technologically feasible should be seconded in an anthropocentric perspective - as defined by the European Commission in its communication of 25 April 2018 (European Commission 2018) - entailing that only those uses that are truly respectful of fundamental values and rights as put forth by EU legislation and constitutional principles should be welcomed. Hence, both research and product design ought to be oriented by such considerations early on.

Having defined the notion of care, in light of its relational and emotional dimension, and having described the essential characteristics of some applications, we need to determine (i) if the different classes of applications here considered do already or could provide care services, and (ii) whether it is desirable and admissible that such services be provided through technological applications, replacing human carers. If a relational and emotional dimension is not only intrinsic to but qualifying of a notion of "care”, it is necessary to determine whether existing and foreseeable devices could indeed meet such standards and thus materially replace human operators before proceeding any further in an ethical, legal and policy debate about the admissibility of the provision of such services through automation,

\subsubsection{Does technology care?}

Emotions are the product of the cooperation of the cognitive, physiological and biological systems, processing sensory information, that is typical, in varying degrees, of all living creatures.

Emotions also represent a universal language that allows humans to communicate with one another at a fundamental level. They may express understanding through non-verbal cues such as tears conveying sadness or sorrow. People understand the emotional state of others through the same neurobiological system. This ability is often associated with the concept of empathy, as well as compassion, and enables humans to modify their social interactions with others and respond appropriately to their desires (Morrison 2004).

In a sympathetic and meaningful care, we give opportunity to those who are being cared for to express their feelings and emotions (Gaita 1999), as well as we experience feelings and emotions as a result of such interaction, establishing a relation. Therefore, if care presupposes experiencing and engaging such emotions, only those who distinctively hold biological features are capable of providing it. 
Evidence suggests that current robotics and AI applications do not possess feelings and emotions (Sparrow and Sparrow 2006) as these devices are unaware of their existence. Robotic and AI are not conscious of perceiving humans, other living beings or even machines as other-than-self. The absolute, radical, objective lack of emotions as well as of self-awareness allow us to exclude the possibility for robots to establish an emotional interaction and thus a true relationship with a human. Therefore, the possibility for current and reasonably foreseeable future machines ${ }^{12}$ to provide care services is highly unlikely, as by definition, they do not "care” (Itoh et al. 2006).

In the context of the scope of this research, social companion robots intending to provide "care" pose relevant ethical concerns, besides potential misuses, requiring more attentive consideration, whereas assistive and monitoring devices are excluded from the focus of the succeeding discussion.

The major concerns rest upon the reaction humans might experience when interacting with such robots. Indeed, despite being incapable of feeling such emotions, they can mimic and simulate them, eliciting a reaction in the user, that is deceptive in nature (Bertolini 2018). If robots may not establish emotional bonds, they can effectively induce human beings to establish a purely delusional relationship, that could lead to their disengagement from reality (Gastmans et al. 2018) and this potentially poses a serious threat to human well-being.

\subsubsection{Dehumanization through isolation: A potential risk}

Where social companion robots are intended to replace human interaction, an incorrect use of these technologies could lead to the isolation of the user. Isolation is per se a reason of concern, beyond deception. The practicality, and cost-effectiveness associated with the use of aforesaid technologies as well as the possibility to observe an improvement in one or more aspects of the end-user's condition, might induce the pervasive replacement of human carers. However, while automation could prove empowering, it should not be deployed at the cost of a reduction of the occasions of human contact. It is commonly acknowledged that humans are social animals, and from the beginning of their lives, they are immersed in social networks (e.g. families, friends, community) (Singer 2018). This interaction develops important social attachment and the proliferation of societies. A substantial reduction in interactions, typi-

12 Here we can transpose the reasoning conducted to exclude the possibility to consider machines responsible for the harmful consequences arising from their operation. If machines were strongly autonomous, then they could even possess emotions and establish relationship, ultimately requiring us to consider them as other forms of intelligent life. Yet no existing technological application or reasonably foreseeable one displays that degree of autonomy and sophistication, and the possibility to achieve it is anything but obvious (Bertolini 2013). 
cal of aging, afflicts the overall physical and psychological well-being of the person (Tesch-Roemer and Huxhold 2019), which negatively affects and increases the risk of issues such as cardiovascular diseases (Seymour and Benning 2009; Cacioppo et al. 2011), depression (Mehta et al. 2002), and dementia (Cacioppo and Hawkley 2009; Cacioppo et al. 2014).

Evidence demonstrates that these technologies bring a range of opportunities and risks. Opportunities include empowering the users and increasing their interaction, for instance simplifying the dynamics of a meal, allowing more users to dine together, and eventually dialogue with a single carer. However, there is a potential risk in certain contexts, unintentionally, of reducing real-time human interaction.

After all, the concept of being cared for exclusively by robots could lead to a decline in the sense of belonging to human society and undermine elderly human qualities, reducing their self-perception of the meaningfulness of their life (Zadro, Williams, and Richardson 2004). This misuse of assistive technologies clearly violates the notion of care we defined above, causing the individual not to be treated as an end-in-himself (Kant 1785), and squarely opposes an anthropocentric approach to AI (European Commission 2018), but even moreso appears to violate the very notion of human dignity, in both its ethical and legal dimension.

\subsection{Human dignity as an ethical and legal concept}

The concept of human dignity, despite widely debated, is expressly proclaimed in most constitutional charters, including the European Charter of Human Rights (henceforth ECHR), as well as in member states' (MS) constitutions. Being a constitutional principle (Feldman 1999), all ethical theories questioning its admissibility and application (Bostrom 2009) may not be taken into account to inform policy decisions, nor may those efforts be seconded, that lead to an interpretation incompatible with its legal notion. In contrary to the claim by Bostrom (2005), dignity might not allow discrimination among human beings due to age, rationality and mental condition, for it is indistinctively and equally possessed by all. The notion may certainly vary over time due to its interpretation and application in courts, but certain strongholds such as the instances above, might not be questioned without challenging the very foundations of the entire constitutional framework ${ }^{13}$.

13 The provision of article 1.1. of the German constitution was introduced by the drafters of the German constitution, right after the collapse of the Nazi regime in the second world war. The notion of human dignity was typically provided as a reaction to Nazism, and its race-superiority rhetoric in order to radically prevent any future occasion of discrimination. The German Basic Law acknowledges human dignity as a guiding principle on fundamental right of the individual which ought not to be sacrificed or discriminated with any other competing rights or values. 
A detailed comparative analysis of its application across MS falls beyond the remit of this paper, however it shall suffice to recall how the principle is often deemed an objective, and external criterion, that limits the individual's self-determination ${ }^{14}$ (Resta 2015; Fabre-Magnan 2007). A freely assumed decision, by a fully rational, conscious, and perfectly informed human being possessing a personal interest, whether economical or not, may still not allow the violation of said principle, for that protects every other human being, and might not be compromised, much less disposed of. Therefore, the notion applies in the case considered in a twofold manner. On the one hand, it forces the adequacy and admissibility of a given application, and of its potential use in the care of fragile individuals to be assessed with respect to such a parameter, per se insufficient, but nonetheless necessary and unavoidable. When determining whether a patient might be fed by an autonomous machine, rather than a human carer, the possibility that it might violate the dignity of the individual is to be taken into consideration, and excluded to allow that use of technology. In this perspective, while the technology appears neutral and possibly empowering, a use that limited or radically excluded occasions for meaningful human interactions might be deemed violating the principle, due to the dehumanization effect briefly recalled above.

On the other hand, it excludes that a choice of the individual might suffice in authorizing a specific use, primarily when deceptive technologies are taken into account (Bertolini 2018), therefore posing a methodological limitation to any further assessment or consideration. All evaluation needs to be objective and not subjective. Even if the single user desired being cared for by an autonomous system, his choice might only be deemed free and valid, once it is established that the specific practice and use is not in violation of human dignity, objectively defined.

\subsection{Discussion and conclusions}

The progressive aging of western societies juxtaposed with the increased dependency ratio poses significant concerns to the welfare systems, which are challenged with the need to provide adequate care services. Robotics certainly represents a powerful asset to manage such radical societal changes. To this end, however, technology needs to be framed within our value system, as primarily reflected in those fundamental principles that ground our society, recalled in our constitutional charters.

14 A prototypical case that is known as le lancer $d u$ nain, addressed by the French Conseil d'Etat (NVwZ 1993, 98). In such a case the free and informed decision of an adult human being to safely - through the adoption of necessary safety measures - let others, in exchange for monetary consideration, compete by tossing him in the air, was deemed inadmissible by the court, for it violated human dignity, intended in an objective and external sense. 
Technology is instrumental and needs to be conceived in a purely anthropocentric perspective (European Commission 2018). Human interaction with technology changes perception as much as people change their way of living through it, by acquiring new possibilities and overcoming what might otherwise be perceived as a constraint and limitation.

The anthropocentric approach calls for policy considerations regarding the kind of technological development society desires and what kind of applications people are willing to welcome into society. In this respect, different approaches are theoretically possible. Transhumanists favor absolute freedom to pursue any advancement possible for any use that a rational and informed party is willing to accept. Alternative philosophical paradigms may be confronted, with the purpose of narrowly defining such an anthropocentric approach, and what measures it could lead policy makers to adopt.

By referring to constitutional values affirmed in our primarily European legal system a specific answer to this theoretical challenge is provided. Indeed, not all philosophical paradigms are equally viable, for they need to fully conform to those fundamental principles and rights previously discussed or be dismissed as unacceptable to ground future policy considerations.

In the case of the transhumanist example, it could be argued that a theoretical system where human dignity is at once deemed measurable (as not all human beings possesses it in equal amount and it is pre-empted by freedom of self-determination), is incompatible to its conception as a fundamental value that belongs to all humans irrespective of any other consideration. It is therefore tainted and may not be applied to determine what uses are admissible.

Having clarified the theoretical paradigm of the analysis, the specific issues of caring for fragile individuals through technology may be addressed. The different functions of care robots have been briefly discussed, distinguishing assistance from monitoring, and caring.

With respect to the latter we have, however, clarified how the notion of care is to be radically differentiated from that of cure. The former entails the emotional engagement, and the relational dimension that at once is the exclusive prerogative of a human being (as only living beings possess emotions, and only humans can establish that essential bond, which also amounts to a virtue) and is so essential to the well-being of the individual, his own self-perception, and self-perceived worth.

It is clear that no application is capable of caring and might only simulate and provide the appearance of such interaction. This could however be deceptive as inducing the individual to engage in a delusional and unrealistic dimension that, within the theoretical framework sketched above, ought to be considered inadmissible, violating the human dignity of the given user and of all other humans overall.

Precisely because of the objective and external dimension of this fundamental constitutional principle, even self-determination would be constrained and limited, 
thereby causing informed consent to be insufficient to enable similar uses of technologies. Such uses of robotics should therefore be overall dismissed.

In all other cases, however, where the application is not primarily intended to engage the user on an emotional level and is therefore not intended to establish a bond and a connection by keeping company or simulating friendship or care, a concern of dehumanization by isolation resides, that needs to be carefully tackled.

Indeed, technology can be largely empowering, providing possibilities that increase the independence of the person being cared for and improving the overall quality of their lives. However, should such applications be intended as a way to radically reduce or worse eliminate professional human care, with the primary aim of abiding budgetary constraints grounded on the observed increase in age-related welfare costs, that would also contrast the anthropocentric perspective on the use of technology, and violate the dignity of the user, thereby being inadmissible in light of our extant legal system.

\section{References}

A Roadmap for US Robotics from Internet to Robotics-CRA.2016. Retrieved from https://cra.org/ccc/ wp-content/uploads/sites/2/2016/11/roadmap3-final-rs-1.pdf

Ageing.2019. Retrieved from https://www.un.org/en/sections/issues-depth/ageing/

American Geriatrics Society Expert Panel on the Care of Older Adults with Multimorbidity.2012. Guiding Principles for the Care of Older Adults with Multimorbidity: An Approach for Clinicians. American 60(10): El - E25

Arendt, Hannah. 1958. The Human Condition. Chicago: The University of Chicago Press.

Aristote, 3. A.1988.The politics. Cambridge: Cambridge University Press.

Aristotle, \& Barnes, Jonathan.1984. The complete works of Aristotle. Princeton: Princeton University Press.

Artificial Intelligence and Transhumanism, The Transhumanism Declaration. http://www.transhumanism.org

Bertolini, Andrea.2013. Robots as Products: The Case for a Realistic Analysis of Robotic Applications and Liability Rules. Law, Innovation and Technology, 5(2), 214-247. doi: http://dx.doi. org/10.5235/17579961.5.2.214

Bertolini, Andrea.2018. Human-Robot Interaction and Deception. Osservatorio del diritto civile e commercial.

Bestic. Retrieved from https://www.camanio.com/us/products/bestic/

Birks et al. 2016. Robotic Seals as Therapeutic Tools in an Aged Care Facility: A Qualitative Study _ Journal of Aging Research)

Bostrom, N. 2009. Dignity and Enhancement. Human Dignity and Bioethics. E. D. Pellegrino, A. Schulman and T. W. Merrill, University of Notre Dame: 173-206.

Bostrom, Nick. 2005. The fable of the dragon tyrant. Journal of Medical Ethics, 31(5), 273-277. doi: http://dx.doi.org/10.1136/jme.2004.009035

Bostrom, Nick.2005. In Defense of Posthuman Dignity. Bioethics, Vol. 19. No. 3.

Bostrom, Nick.2008. Dignity and Enhancement in Schulman, A.2008. Human dignity and bioethics: Essays commissioned by the Presidents Council on Bioethics. Washington, D. C.: Presidents Council on Bioethics.

Cacioppo JT and Hawkley LC. 2009. Perceived social isolation and cognition. Trends Cognitive Sci. doi: http://dx.doi.org/10.1016/j.tics.2009.06.005 
Cacioppo JT, Hawkley LC, Norman GJ and Berntson GG.2011. Social isolation. Ann NY Acad Sci; 123:11:17-22

Cacioppo S, Capitanio JP and Cacioppo JT.2014. Toward a neurology of loneliness. Psychol. Bull. 140:6:1464-1504

Calzo, Antonello Lo.2018. Il Diritto All'Assistenza E Alla Cura Nella Prospettiva Costituzionale Tra Eguaglianza E Diversità. Associazione Italiana Del Costituzionalisti.

Coeckelbergh, Mark.2013. Human Being @ Risk. Philosophy of Engineering and Technology. doi: http://dx.doi.org/10.1007/978-94-007-6025-7

Constitution of the World Health Organization. 2006. Geneva: WHO.

Curzer, Howard J. 2007. Aristotle: Founder of the Ethics of Care. The Journal of Value Inquiry. 41.

Dag, Murin, Svanelov Eric,Gustafsson Christine.2017. Experience of using Bestic, and eating aid for people with intellectual disabilities. Journal of Intellectual Disablities .vol. 21(1).

Demange, M., Lenoir, H., Pino, M., Cantegreil-Kallen, I., Rigaud, A. S., \& Cristancho-Lacroix, V. 2018. Improving well-being in patients with major neurodegenerative disorders: Differential efficacy of brief social robot-based intervention for 3 neuropsychiatric profiles. Clinical Interventions in Aging, Volume 13, 1303-1311 https://doi.org/10.2147/CIA.S152561

DeVos Annemarie. 2017. Optimal Care for Elderly in Transition ...Lesson Leaned. Journal of Gerontology \& Geriatric Research. http://dx.doi.org/10.4172/2167-7182.1000392

Engster, Daniel.2007. The Heart of Justice; Care Ethics and Political Theory. Oxford: Oxford University Press.

European Commission, (2018). Communication from the Commission to the European Parliament, the European Council, the Council, the European Economic and Social Committee and the Committee of the Regions. Artificial Intelligence for Europe. Brussels, European Commission.

European Union, Charter of Fundamental Rights of the European Union, 26 October 2012, 2012/C 326/02, available at: https://www.refworld.org/docid/3ae6b3b70.html [accessed 11 May 2019]

Fabre-Magnan, Muriel. 2007. „La dignité en droit: un axiome.“ Revue interdisciplinaire d'études juridiques 58(1): 1-30.

Falicov, Celia. J. 2007. Working with Transnational Immigrants: Expanding Meanings of Family, Community, and Culture. Family Process, 46(2), 157-171.https://doi. org/10.1111/j.1545-5300.2007.00201.x

Feldman, David. 1999. „Human Dignity as a Legal Value - Part I.“ Public Law: 682.

Flandorfer, Priska. 2012. Population Ageing and Socially Assistive Robots for Elderly Persons: The Importance of Sociodemographic Factors for User Acceptance. International Journal of Population Research. 1-13.

Gaita, Raimond. 1999. A common humanity: Thinking about love $\&$ truth \& justice. Melbourne: Text Publishing, pp. 263-268.

Germany: Basic Law for the Federal Republic of Germany [Germany], 23 May 1949, available at: https://www.refworld.org/docid/4e64d9a02.html [accessed 11 May 2019]

Hamada, et al. 2008. Robot Therapy as for Recreation for Elderly People with Dementia - Game Recreation Using a Pet-type Robot__Proceedings of the 17th IEEE International Symposium on Robot and Human Interactive Communication, Technische Universität München, Munich, Germany.

Horizon 2020. Retrieved from https://ec.europa.eu/programmes/horizon2020/en

http://dx.doi.org/10.1155/2012/829835

Itoh, K., Miwa, H., Zecca, M., Takanobu, H., Roccella, S., Carrozza, M. C., Takanishi, A. (n. d.). Mechanical Design of Emotion Expression Humanoid Robot WE-4RII. CISM Courses and Lectures Romansy 16,255-262. doi:10.1007/3-211-38927-x_33 
Jain, Advait., \& Kemp, Charles. C. 2009. EL-E: An assistive mobile manipulator that autonomously fetches objects from flat surfaces. Autonomous Robots,28(1), 45-64. doi:10.1007/ s10514-009-9148-5

Japan Promoting Inclusive Growth for an Aging Society. Retrieved from https://www.oecd.org/about/ secretary-general/BPS-Japan-EN-April-2018.pdf

JIBO (2019): The World's First Social Robot for the Home. Retrieved from https://www.youtube.com/ watch?v=H0h20jRA5M0

Johnson, K.2019. Softbank Robotics enhances Pepper the robot's emotional intelligence. Retrieved from https://venturebeat.com/2018/08/28/ softbank-robotics-enhances-pepper-the-robots-emotional-intelligence/

Kant. Emanuel. 1785. The groundwork of the metaphysics of moral.

Leininger, M. (1988). Caring: An essential human need. Detroit: Wayne State University Press.

Luciano Floridi, Philosophy and Computing: An Introduction. Retrieved from https://www.researchgate.net/publication/257820666_Luciano_Floridi_Philosophy_and_Computing_An_Introduction

Lutz, Wolfgan., Sanderson, Warren., \& Scherbov, Sergei.2008. The coming acceleration of global population ageing. Nature, 451(7179), 716-719. http://dx.doi.org/10.1038/nature065165

MacIntyre, Alasdair. C.1999. Dependent rational animals: Why human beings need the virtues. Chicago: Open Court

Mehta KM, Yaffe K and Covinsky KE. Cognitive impairment, depressive symptoms and functional decline in older people. JAGS 2002; 50:6:1045-1050.

Mickelburgh, R. 2004. Meet Pearl - she's the robo-nurse designed to look after the elderly. Retrieved from https://www.telegraph.co.uk/news/worldnews/northamerica/usa/1457427/Meet-Pearlshes-the-robo-nurse-designed-to-look-after-the-elderly.html

Morrison, Jason. 2004. Understanding Others by Understanding the Self: Neurobiological Models of Empathy and their Relevance to Personality Disorders. Retrieved from https://www.ncbi.nlm.nih. gov/pmc/articles/PMC2538737/

Noddings, Nel. 1984. Caring: A feminine approach to ethics and moral education. Berkeley: University of California Press.

Noddings, Nel. 2013. Starting at home: Caring and social policy. Charlesbourg, Québec: Braille Jymico.Number of Workers per Retiree Declines Worldwide. (2015, December 22). Retrieved from https://yaleglobal.yale.edu/content/number-workers-retiree-declines-worldwide

Nylander, S., Ljungblad, S., \& Villareal, J. J. 2012. A complementing approach for identifying ethical issues in care robotics - grounding ethics in practical use. 2012 IEEE RO-MAN: The 21st IEEE International Symposium on Robot and Human Interactive Communication. doi:10.1109/ roman.2012.6343849

PARO Therapeutic Robot. Retrieved from http://www.parorobots.com/

Pollack Martha. et al. 2002. Pearl: A Mobile Robotic Assistant for Elderly. Workshop on Automation as Caregiver: The Role of Intelligent Technology in Elder Care.

Reich, Warren. Thomas. 1995. Encyclopedia of bioethics. New York u. a.: MacMillan Libr. Reference u. a.

Reich, Warren. Thomas. 2001. The Care-Based Ethic of Nazi Medicine and the Moral Importance of What We Care About. American Journal of Bioethics, 1(1), 64-74. doi:10.1162/152651601750079195

Resta, Giorgio.2015. Human Dignity. in A. Popovici and L. Smith, eds., McGill Companion to Law, online at https://mcgill.ca/companion/list/human-dignity

Retrieved from http://rtc.nagoya.riken.jp/RIBA/index-e.html

Salvini, Pericle.1970. On Ethical, Legal and Social Issues of Care Robots. Retrieved from https://link. springer.com/chapter/10.1007/978-3-319-12922-8_17(2015) 
Schmalzbauer, L. 2010. Disruptions, Dislocations, and Inequalities: Transnational Latino/a Families Surviving the Global Economy. North Carolina Law Review. Vol 88.

Seymour J and Benning TB.2009. Depression, cardiac mortality and all-cause mortality. Advances in psychiatric treatment; 15:107-113

Sharkey, A., \& Sharkey, N. 2010. Granny and the robots: Ethical issues in robot care for the elderly. Ethics and Information Technology, 14(1), 27-40. doi:10.1007/s10676-010-9234-6

Sharkey, Amanda.2014. Robots and Human Dignity: A Consideration of the Effects of Robot Care on the Dignity of Older People. Ethics and Information Technology, vol. 16, no. 1, 2014, pp. 63-75., doi:10.1007/s10676-014-9338-5.

Sheba et al.2018. Development of Rehabilitative Multimodal Interactive Pet Robot for Elderly Residents_International Conference on Robotics and Smart Manufacturing (RoSMa2018)_Procedia Computer Science 133, 401-408.

Shibata, T., \& Wada, K. (2011). Robot Therapy: A New Approach for Mental Healthcare of the Elderly A Mini-Review. Gerontology,57(4), 378-386. doi:10.1159/000319015

Smith, V. (1992). Circles of Care: Work and Identity in Womens Lives. Emily K. Abel , Margaret K. NelsonManaging Lives: Corporate Women and Social Change. Sue J. M. FreemanThe Experience and Meaning of Work in Womens Lives. Hildreth Y. Grossman , Nia LanSoler, M. V., Agüera-Ortiz, L., Rodríguez, J. O., Rebolledo, C. M., Muñoz, A. P., Pérez, I. R., . . Martín, P. M. (2015). Social robots in advanced dementia. Frontiers in Aging Neuroscience, 7. doi:10.3389/fnagi.2015.00133

Sparrow, Robert., \& Sparrow, Linda. 2006. In the hands of machines? The future of aged care. Retrieved from https://link.springer.com/article/10.1007/s11023-006-9030-6

Takefumi Kikusui, James T Winslow and Yuji Mori. 2006. Social buffering: relief from stress and anxiety, philosophy transaction of the royal society. doi:10.1098/rstb.2006.1941

Tesch-Roemer, C., \& Huxhold, 0. 2019. Social Isolation and Loneliness in Old Age. Oxford Research Encyclopedia of Psychology. doi:10.1093/acrefore/9780190236557.013.393

The German Supreme Courts'legislation on the peep-show 15 DEC 1981, BVerwG

The use of care robots in aged care: A systematic review of argument-based ethics literature. 2017. Retrieved from https://www.sciencedirect.com/science/article/pii/S0167494317302790

Tronto, J. C. 2015. Who Cares?: How to Reshape a Democratic Politics. Cornell University Press.

Tronto, Joan. 2015. Moral boundaries: A political argument for an ethic of care. Place of publication not identified: Routledge.

Vandemeulebroucke, T., Casterlé, B. D., \& Gastmans, C. 2018. The use of care robots in aged care: A systematic review of argument-based ethics literature. Archives of Gerontology and Geriatrics,74, 15-25. doi:10.1016/j.archger.2017.08.014

Wackenheim v. France, Comm. 854/1999, U. N. Doc. A/57/40, Vol. II, at 179 (HRC 2002).

Winner, S. 2007. Beam me inside, Scotty! Assisted Living Consult. https://www.assistedlivingconsult.com/issues/03-04/alc78-BeamMeUp-719a.pdf

World Population Prospects: The 2017 Revision | Multimedia Library - United Nations Department of Economic and Social Affairs. (n. d.). Retrieved from https://www.un.org/development/desa/ publications/world-population-prospects-the-2017-revision.html

Zadro, Lisa, et al. "How Low Can You Go? Ostracism by a Computer Is Sufficient to Lower Self-Reported Levels of Belonging, Control, Self-Esteem, and Meaningful Existence." Journal of Experimental Social Psychology, vol. 40, no. 4, 2004, pp. 560-567., doi:10.1016/j.jesp.2003.11.006. 